\title{
A Case Study on Parameters Influencing Dust Accumulation on CSP Reflectors
}

\author{
Selene Pennetta ${ }^{1}$, Francesco Anglani ${ }^{1}$, John Barry ${ }^{1}$ and Shengzhe $\mathrm{Yu}^{2}$ \\ 1. Energy and Process Engineering, Queensland University of Technology, Brisbane 4000, Australia \\ 2. Energy and Sustainable Engineering Process, University of Queensland, Saint Lucia 4072, Australia
}

Received: December 10, 2015 / Accepted: January 05, 2016 / Published: February 29, 2016.

\begin{abstract}
The effect of dust accumulation on CST (concentrated solar thermal) reflectors is to deflect, or scatter, incident light rays missing the receiver with a subsequent power produced loss. Dust fouling is site specific, and the understanding of interactions between different weather and or environmental parameters is crucial for plant profitability. This research intends to provide useful insights on the interaction between the most relevant weather parameters affecting soil accumulation. Results show a significant dependency of dust concentration versus humidity and ambient temperature, as well as a nexus between wind speed and ambient temperature seems to exist. As long as the temperature decreases an increase of humidity and dust concentration occurs. This phenomenon takes place mostly overnight till the first hours of the morning. Therefore, mirror's reflectance looks extremely affected by dust accumulation because of high humidity rate during the night and dews of early morning. Further investigations are required to validate the hypothesis that, a more effective cleaning activitie to restore plants' reflectivity are to be carried out during the early morning.
\end{abstract}

Key words: CSP plant, reflectivity degradation, dust accumulation, dust concentration, environmental factors.

\section{Introduction}

During last three decades, the world energy market has experienced a remarkable change with the introduction of renewable source. PV (photovoltaic), geothermal, Eolic and CST (concentrated solar thermal) energy systems have revolutionized the energy market mix production. The research community and solar energy companies have put their efforts to make these resources more reliable and attractive to governments and institutions, carrying out many improvements over the years.

Enhancements in the manufacturing process, materials selection, scheduling, planning and development have greatly reduced the cost of solar technology.

The adoption of CST technologies in the last twenty

Corresponding author: Selene Pennetta, senior research assistant, research fields: energy and process engineering department, renewable energy and asset management. years, thanks to its dispatchability, has led to a diversified renewable energy market, mainly in Southern Europe and the USA. The advantage of thermal storage with CSP (concentrated solar power) plants is that, it provides flexible on-demand energy.

Recent experience in Spain has shown that, appropriate site location is important to get the maximum performance out of CST technology. CSP plants work with high efficiency only in arid to semi-arid regions where DNI (direct normal irradiance), is typically above $2,000 \mathrm{kWh} / \mathrm{m}^{2}$ annually [1-3].

Different studies on power loss generation due to dust settlement on photovoltaic panels, evacuated tubes and CST reflectors, have been conducted in the last thirty years. Researchers have found glass tube transmittance drop of up to $38 \%$ in a solar desalination plant located in UAE [4]. CST reflectors reflectance decreases up to $8.8 \%$ have been found in several experimental studies within a reasonable time of exposure. By increasing the time intervals between 
cleaning, a power loss up to $60 \%$ has been observed. Research findings draw the attention on the transmittance drop from $88 \%$ to $33 \%$ after 30 days of exposure for a glass plate at different angles of tilt [5].

Because of the adverse impact that, mirror soiling has upon energy production at CST power plants all operational plants carry out a schedule of regular mirror cleaning. The labour and equipment cost of cleaning do impact the LCOE (levelised cost of energy) bottom line. In modern CST plants, the maintenance activity related to mirror cleanliness adds approximately $8 \%$ to the LCOE [6]. The overarching purpose of this study on dust accumulation on CST reflectors is to investigate ways and means for optimising mirror cleaning processes.

It is expected that, dust accumulation and reflector-surface soiling will be greatly influenced by location and by weather conditions. It is expected that, dust composition and particle size will be different for different sites, as will weather conditions [7]. Dust particle size and composition are expected to have an impact upon stickiness and light scattering, these are two significant parameters that influence mirror soiling. As regarding weather conditions, while heavy rain is useful for cleaning mirrors, light rain or heavy dew may increase dust adhesion and enable cementation of water-soluble dust [8-13].

This study examines dust accumulation at a single location, at Collinsville, $100 \mathrm{~km}$ inland on the tropical North East coast of Australia (Fig. 1). This study does not investigate mirror soiling directly, that is a topic covered by another paper soon to be published. This study aims at identifying the weather conditions responsible of CST plant reflectivity degradation through the analysis of parameters, such as ambient temperature, relative humidity and wind speed as function of time. In addition, this study includes preliminary characterisation of particle composition and particle size. We have identified the main factors influencing dust settlement on flat surfaces as reported in Fig 2.

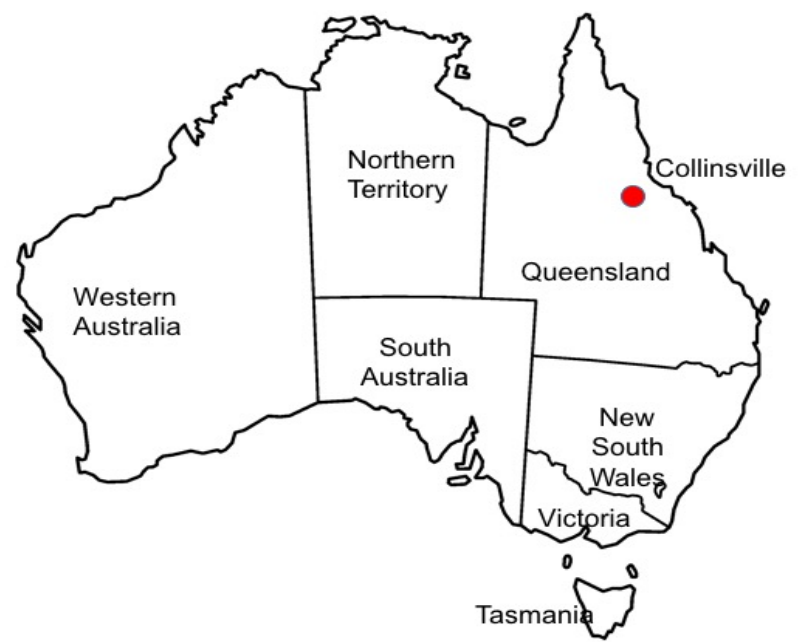

Fig. 1 Dust monitor location-Collinsville.

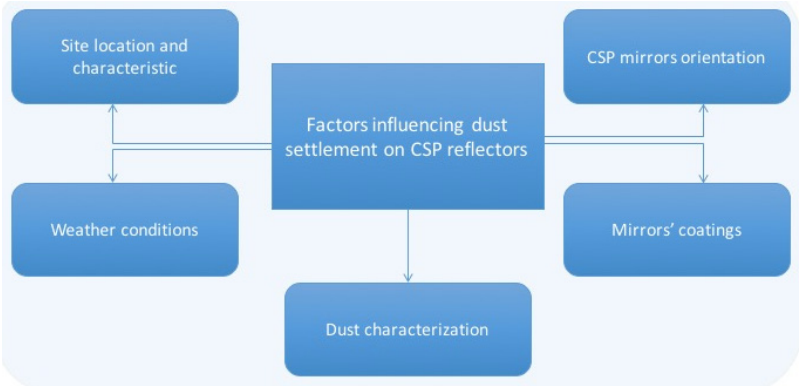

Fig. 2 Factors influencing dust settlement.

\section{Measurement Setup and Data Description}

\subsection{Measurement System and Site Description}

Data on airborne particles has been collected at Collinsville in the northern part of Queensland, Australia through a real time-monitor equipped with swappable $47 \mathrm{~mm}$ in size, Teflon filters.

The real-time monitoring system (Fig. 3) has been installed in Collinsville and it started gathering data since May 16, 2013. The real-time monitor is surrounded by an active coal-mine and a decommissioned coal power station of 190 MW on the South-West, by a roadway on the North-East side and by flat lands with rich vegetation on the North and South areas. The environment of dust monitoring system is shown in Google Map at the following coordinates $20^{\circ} 32^{\prime} 36^{\prime \prime} \mathrm{S} 147^{\circ} 48^{\prime} 25^{\prime \prime} \mathrm{E}$ (Fig. 4).

The E-sampler (Fig. 5) is characterised by a solar power panel, a wind speed and direction sensor model 


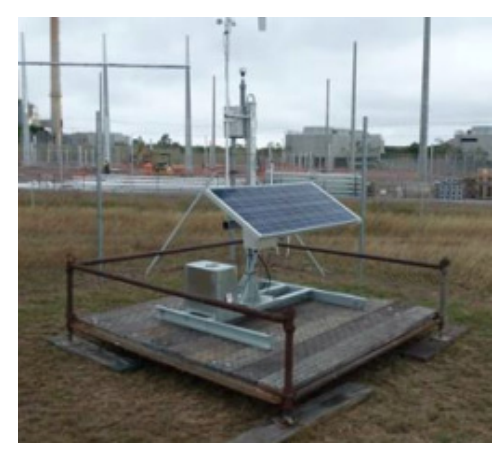

Fig. 3 Real-time monitor station.

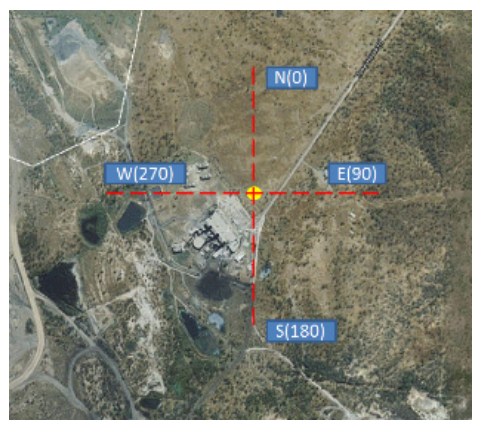

Fig. 4 Collinsville map detail.

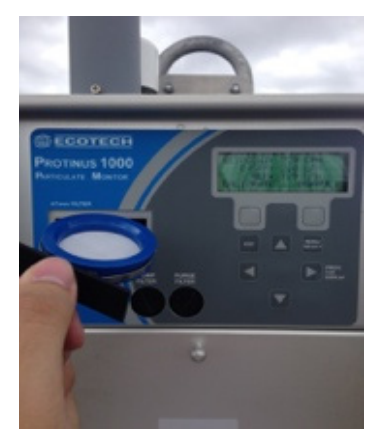

Fig. $547 \mathrm{~mm}$ Teflon filters.

034B from Met One instruments (Fig. 6), and a mounting frame. Since April 2014, the relative humidity sensor model 083/593A (Fig. 7), has been added to the real time monitoring station with the accuracy about $\pm 2 \%$ from 0 to 100 .

Dust concentration data have been collected using the Ecotech E-sampler light scattering monitor and technical specifications are summarized in Table 1.

This real-time monitor is characterized by a dual technology, the light scattering technology and the gravimetric method. The first one provided real time measurements of airborne particulate by light scatter, while the second provides the calibration factor for the measurement of the light scattering, and particulate

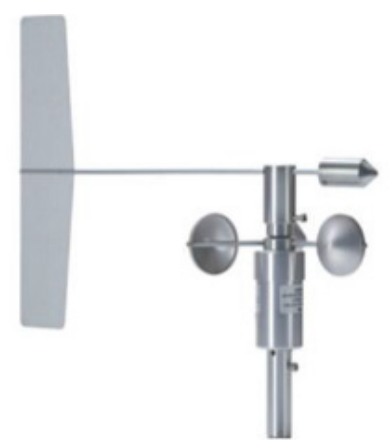

Fig. 6 Wind speed sensor.

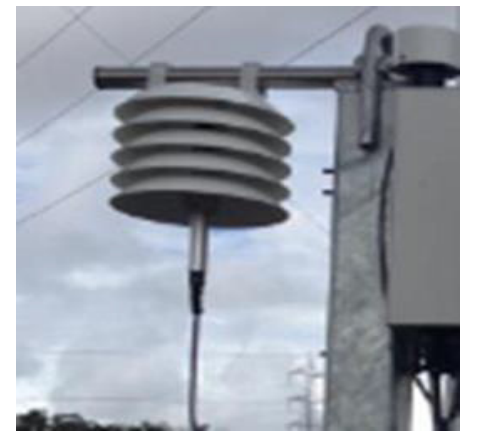

Fig. 7 Humidity sensor.

Table 1 Ecotech E-sampler light scattering technical specifications.

\begin{tabular}{ll}
\hline & Ecothech E-sampler \\
\hline Smallest data/reading resolution & $1 \mathrm{~min}$ \\
& $0-500 \mu \mathrm{g} / \mathrm{m}^{3}$ or \\
& $0-1,000 \mu \mathrm{g} / \mathrm{m}^{3}$ or \\
Range & $0-10,000 \mu \mathrm{g} / \mathrm{m}^{3}$ or \\
& $0-65,000 \mu \mathrm{g} / \mathrm{m}^{3}$ \\
& $\pm 3 \mu \mathrm{g} / \mathrm{m}^{3}$ or \\
Resolution & $2 \%$ of reading \\
Operating temperature & $-10-50^{\circ} \mathrm{C}$ \\
Battery bank size @ $12 \mathrm{~V}$ & $100 \mathrm{Ah}$ \\
Solar array size & $125 \mathrm{~W}$ \\
\hline
\end{tabular}

characterization for size and properties analysis by the $47 \mathrm{~mm}$ filter system (Fig. 5).

Each 30 days the filter is exchanged with a new one and dust accumulated is analysed in Queensland University of Technology laboratories for concentration, size and physical and chemical analysis. The real time monitoring system is remote controlled by the Comet software providing the data of dust concentration, wind speed, wind direction, temperature, humidity, date and time for each filter collected from the monitor. 
To provide the best accuracy of the dust concentration, a monitor calibration has been carried out, in order to determine the " $K$-factor" as the ratio between the dust accumulated on the $47 \mathrm{~mm}$ filter and the total concentration measured by the light scattering method at the same time interval.

The average value of the $K$-factor for the system is 4.5 .

\subsection{Data Description}

This data analysis considers about 12 months set of data from 15/06/2013 to 31/05/2014 recorded at Collinsville in state of Queensland, Australia. The dataset presents different time sampling rate.

At the beginning, the E-sampler monitor has been set at $1 \mathrm{~min}$ of time sampling rate that is not sufficient for the amount of memory available to store all the records during one day. Indeed, once the memory is full, the E-sampler proceeds to overwrite the oldest info with the new ones and to prevent this, a second time sampling rate has been chosen at 15 min leaving enough time for dust accumulating on filter. Moreover three months of missing data from November 2013 to March 2014 are due to Telstra $3 \mathrm{G}$ modem connection issues.

\section{Methodology}

The SEM (scanning electron microscope) analysis of the dust collected onto the $47 \mathrm{~mm}$ Teflon filters has provided the chemical composition of the soil collected during the prefixed time of interval.

Several points of interest have been chosen to widening the sample chemical characterisation (Figs. 8 and 9).

To determine particles size, the ImageJ software has been used for this purpose. We have imported the high quality images generated during SEM analysis into ImageJ.

Raw data related to dust concentration, wind speed, and ambient temperature collected by the Ecotech E-sampler have been analysed with Microsoft Excel to identify relations or trends between parameters as reported above.

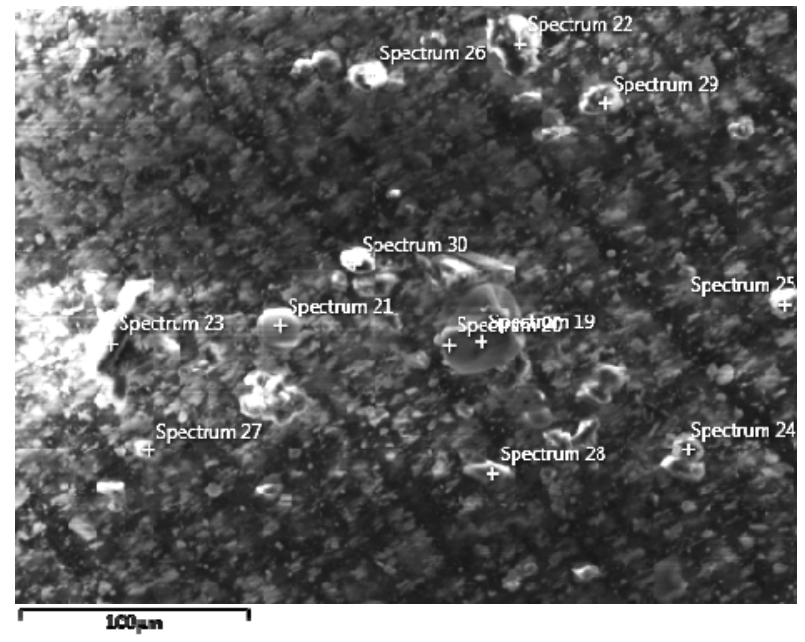

Fig. 8 SEM analysis of dust fileter collected in April 2014.

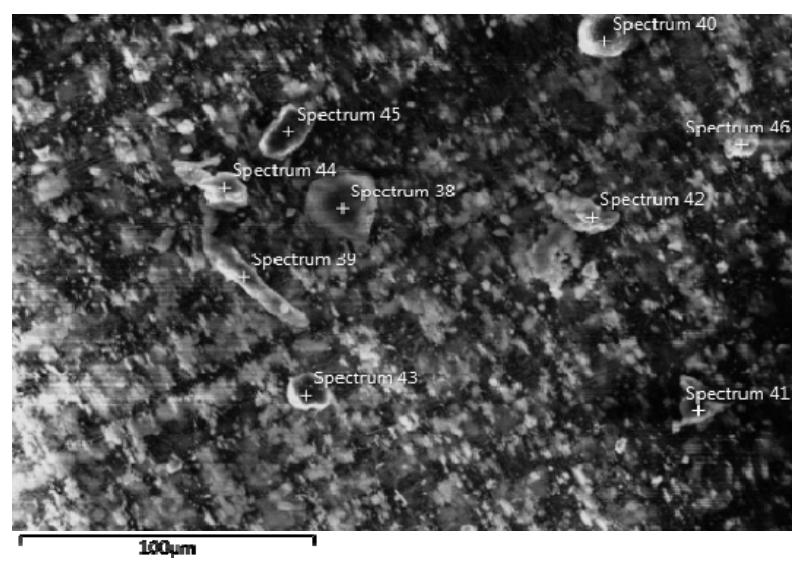

Fig. 9 SEM analysis of dust fileter collected in May 2014.

\section{Results and Discussion}

\subsection{Dust Analysis and Characterization}

Dust characterization has been conducted in QUT (Queensland University of Technology) labs with the ZEISS electronic microscope. The analysis of several samples of dust accumulated on filters shows an average particle size of $15 \mu \mathrm{m}$.

Tables 2 and 3 in addition to Figs. 10 and 11, show compositional analysis of typical particle types. The relative elemental composion is tabulated as oxides and is refernced to typical minerals. The analysis in Table 2 shows large amount of $\mathrm{SiO}_{2}$ and $\mathrm{Al}_{2} \mathrm{O}_{3}$ with minor components of $\mathrm{Na}, \mathrm{Mg}$, etc. This is characteristic of an aluminosilicate mineral, that is, clay. Table 3 has a major component which is referenced as albite and 


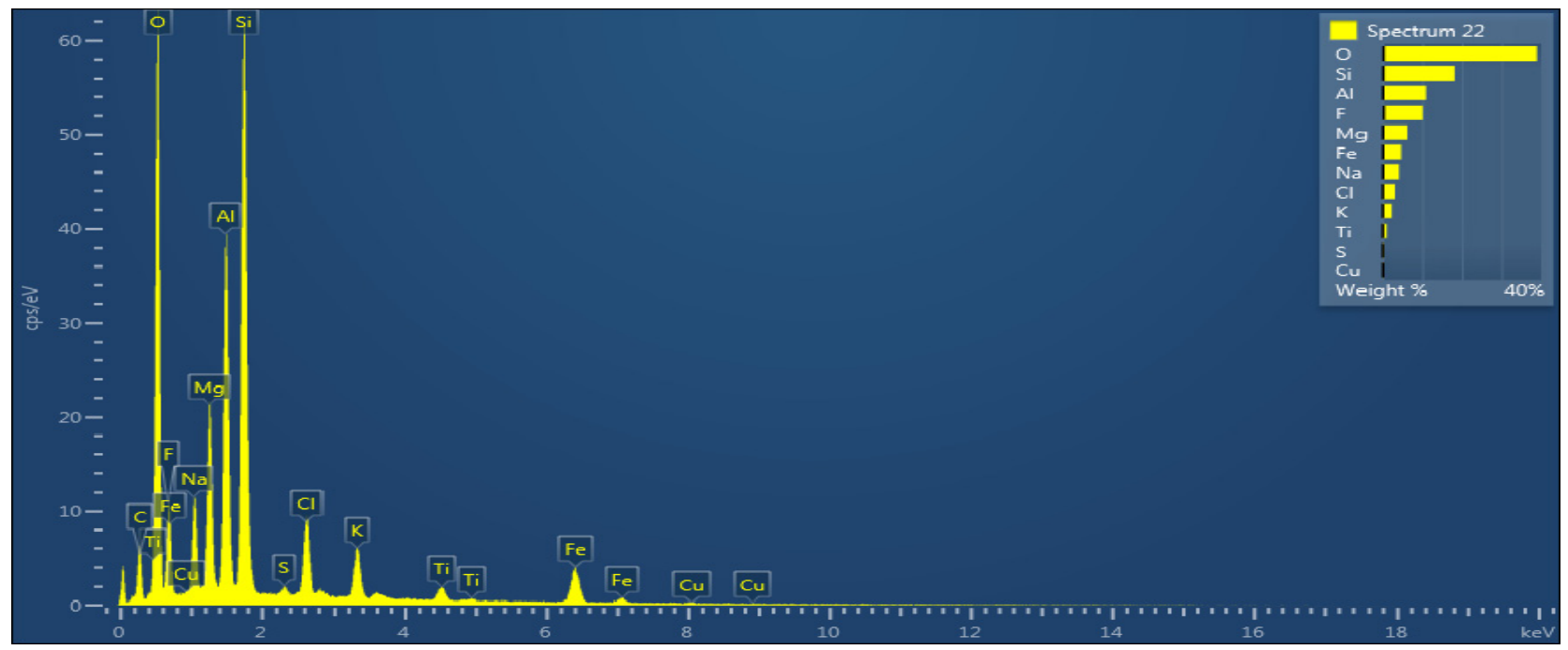

Fig. 10 Spectrum of dust composition during April 2014.

Table 2 Chemical composition of dust filter in April 2014.

\begin{tabular}{llllll}
\hline Element & $\begin{array}{l}\text { Apparent } \\
\text { concentration }\end{array}$ & $k$ ratio & W.t.\% & W.t.\% Sigma & Standard label \\
\hline $\mathrm{O}$ & & & 38.91 & & $\mathrm{CaF}_{2}$ \\
$\mathrm{~F}$ & 13.45 & 0.02641 & 10.08 & 0.27 & $\mathrm{Albite}$ \\
$\mathrm{Na}$ & 4.95 & 0.02087 & 4.09 & 0.09 & $\mathrm{MgO}$ \\
$\mathrm{Mg}$ & 6.44 & 0.04270 & 6.19 & 0.09 & $\mathrm{Al}_{2} \mathrm{O}_{3}$ \\
$\mathrm{Al}$ & 11.97 & 0.08599 & 10.94 & 0.11 & $\mathrm{SiO}_{2}$ \\
$\mathrm{Si}$ & 19.52 & 0.15466 & 18.15 & 0.13 & $\mathrm{FeS}_{2}$ \\
$\mathrm{~S}$ & 0.34 & 0.00293 & 0.30 & 0.04 & $\mathrm{NaCl}$ \\
$\mathrm{Cl}$ & 3.63 & 0.03172 & 3.10 & 0.06 & $\mathrm{KBr}$ \\
$\mathrm{K}$ & 3.10 & 0.02627 & 2.27 & 0.05 & $\mathrm{Ti}$ \\
$\mathrm{Ti}$ & 1.17 & 0.01170 & 1.00 & 0.05 & $\mathrm{Fe}$ \\
$\mathrm{Fe}$ & 5.60 & 0.05603 & 4.67 & 0.11 & $\mathrm{Cu}$ \\
$\mathrm{Cu}$ & 0.35 & 0.00347 & 0.30 & 0.08 & \\
\hline Total & & & 100.00 & & \\
\hline
\end{tabular}

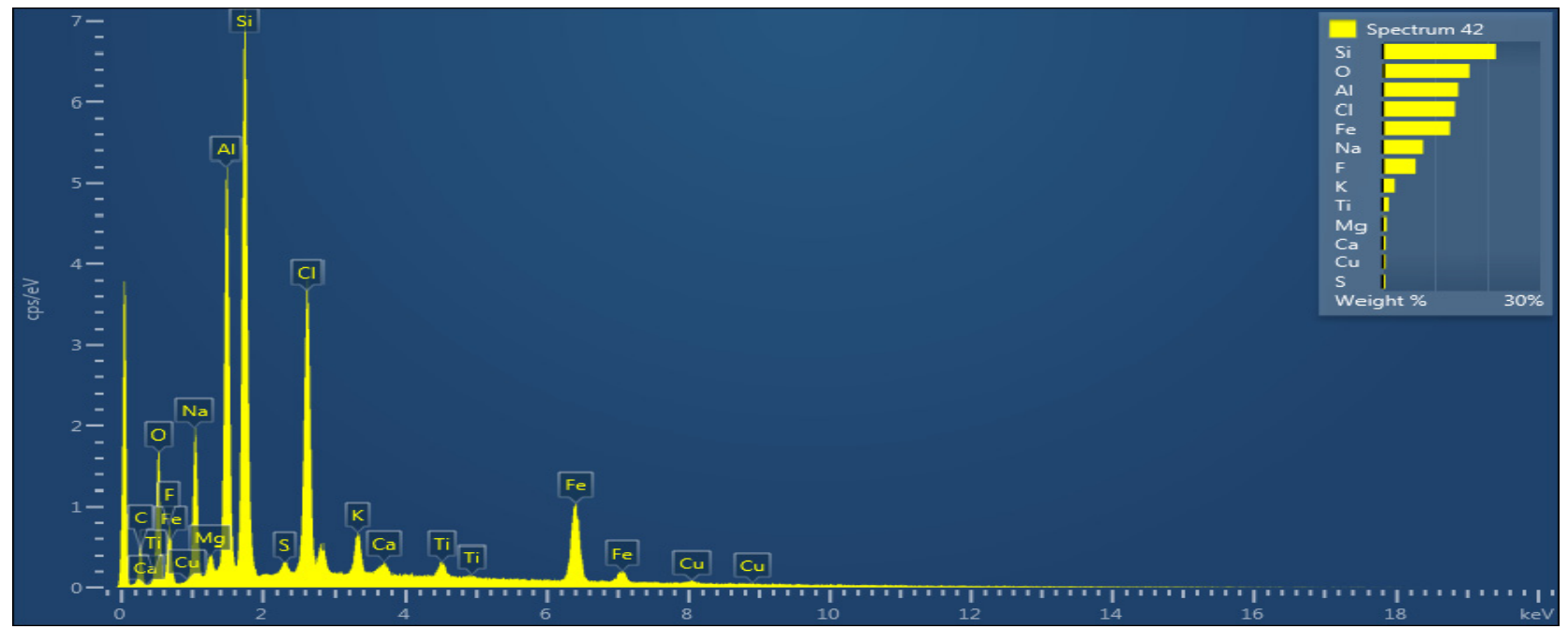

Fig. 11 Spectrum of dust composition during May 2014. 
Table 3 Chemical composition of dust filters in May 2014.

\begin{tabular}{llllll}
\hline Element & $\begin{array}{l}\text { Apparent } \\
\text { concentration }\end{array}$ & $k$ ratio & W.t.\% & W.t.\% Sigma & Standard label \\
\hline $\mathrm{O}$ & 11.56 & 0.03888 & 16.57 & 0.30 & $\mathrm{SiO}_{2}$ \\
$\mathrm{~F}$ & 8.30 & 0.01629 & 6.38 & 0.20 & $\mathrm{CaF}_{2}$ \\
$\mathrm{Na}$ & 7.02 & 0.02961 & 7.79 & 0.13 & $\mathrm{Albite}$ \\
$\mathrm{Mg}$ & 0.64 & 0.00424 & 0.88 & 0.06 & $\mathrm{MgO}$ \\
$\mathrm{Al}$ & 12.09 & 0.08682 & 14.45 & 0.14 & $\mathrm{Al}_{2} \mathrm{O}_{3}$ \\
$\mathrm{Si}$ & 16.84 & 0.13345 & 21.59 & 0.17 & $\mathrm{SiO}_{2}$ \\
$\mathrm{~S}$ & 0.48 & 0.00410 & 0.60 & 0.06 & $\mathrm{FeS}_{2}$ \\
$\mathrm{Cl}$ & 11.61 & 0.10147 & 13.83 & 0.14 & $\mathrm{NaCl}$ \\
$\mathrm{K}$ & 2.24 & 0.01900 & 2.38 & 0.08 & $\mathrm{KBr}$ \\
$\mathrm{Ca}$ & 0.69 & 0.00613 & 0.72 & 0.07 & $\mathrm{Wollastonite}$ \\
$\mathrm{Ti}$ & 1.06 & 0.01063 & 1.26 & 0.08 & $\mathrm{Ti}$ \\
$\mathrm{Fe}$ & 11.31 & 0.11313 & 12.88 & 0.19 & $\mathrm{Fe}$ \\
$\mathrm{Cu}$ & 0.58 & 0.00576 & 0.68 & 0.15 & $\mathrm{Cu}$ \\
\hline Total & & & 100.00 & & \\
\hline
\end{tabular}

$\mathrm{NaCl}$, but it is more likely to be sea-salt $(\mathrm{NaCl})$ mixed with small amounts of clay.

\subsection{Data Analysis of Data from Dust Monitor}

Each parameter has been plotted over the time of acquisition and interestingly dust accumulation, shows a stratified trend as probable consequence of $\mathrm{ADC}$ (analog-to-digital converter) (Fig. 12).

To outline the stratified data distribution, a logarithmic concentration of soil is represented in the same interval of time selected (Fig. 13).

Plotting dust accumulation versus a long time frame is dominated by the high dust events which, in fact are uncommon (more on this further below), and does not provide a helpful insight about the variations of dust concentration during the day. On the other hand, considering one week or two weeks time intervals, it is possible to observe a significant fluctuation of airborne particles concentration that is dependent upon relative humidity variation.

As shown in Fig. 14, dust concentration increases as at the point in time where relative humidity decreases. This is most evident in the time just before dawn up until mid- morning. This is the point in time when humidity is high and air temperature is starting to increase (Fig. 15). It is notable that, the humidity is

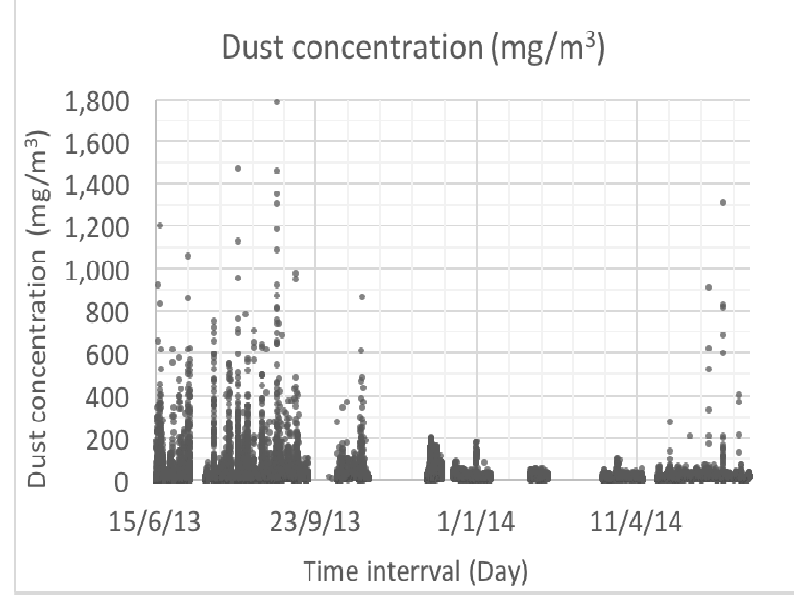

Fig. 12 Dust concentration from June 15, 2013 to May 31, 2014.

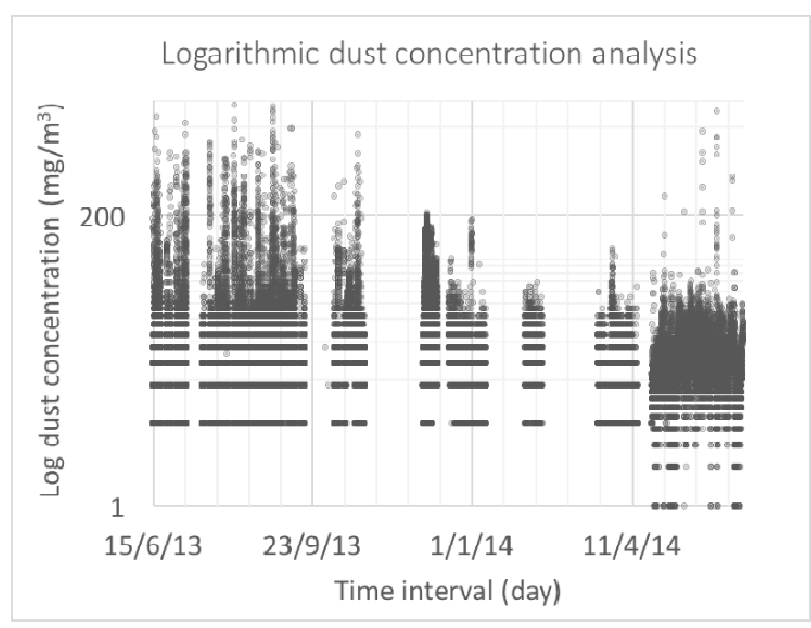

Fig. 13 Logarithmic plot of dust concentration from June 15, 2013 to May 31, 2014. 


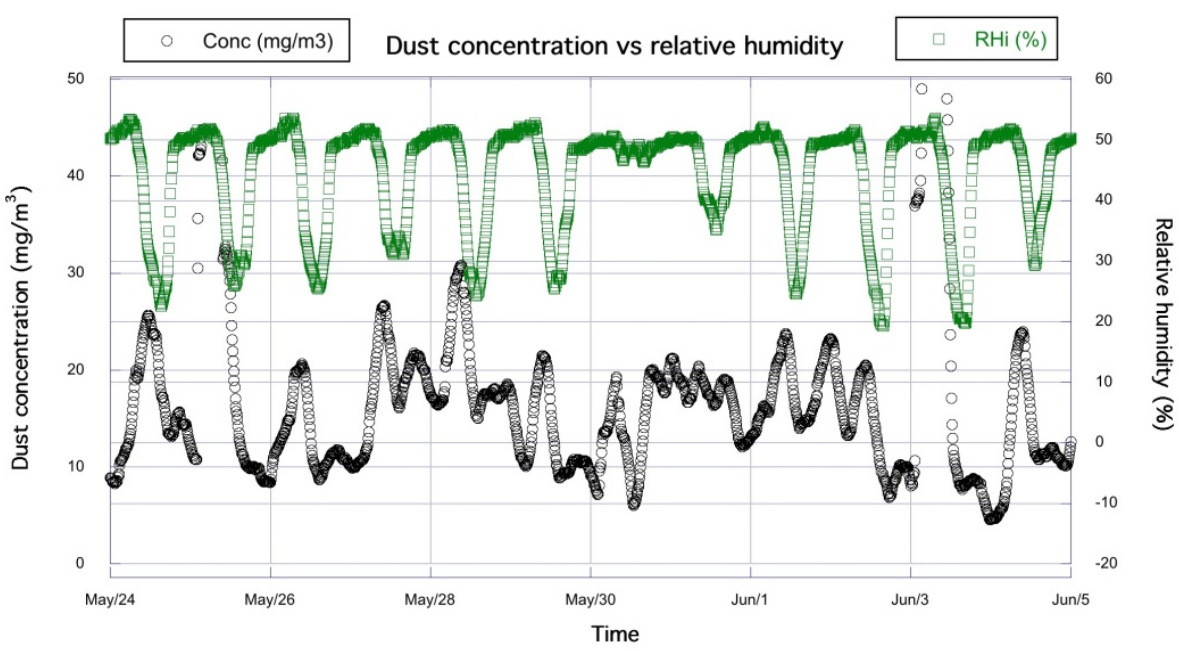

Fig. 14 Dust concentration versus relative humidity.

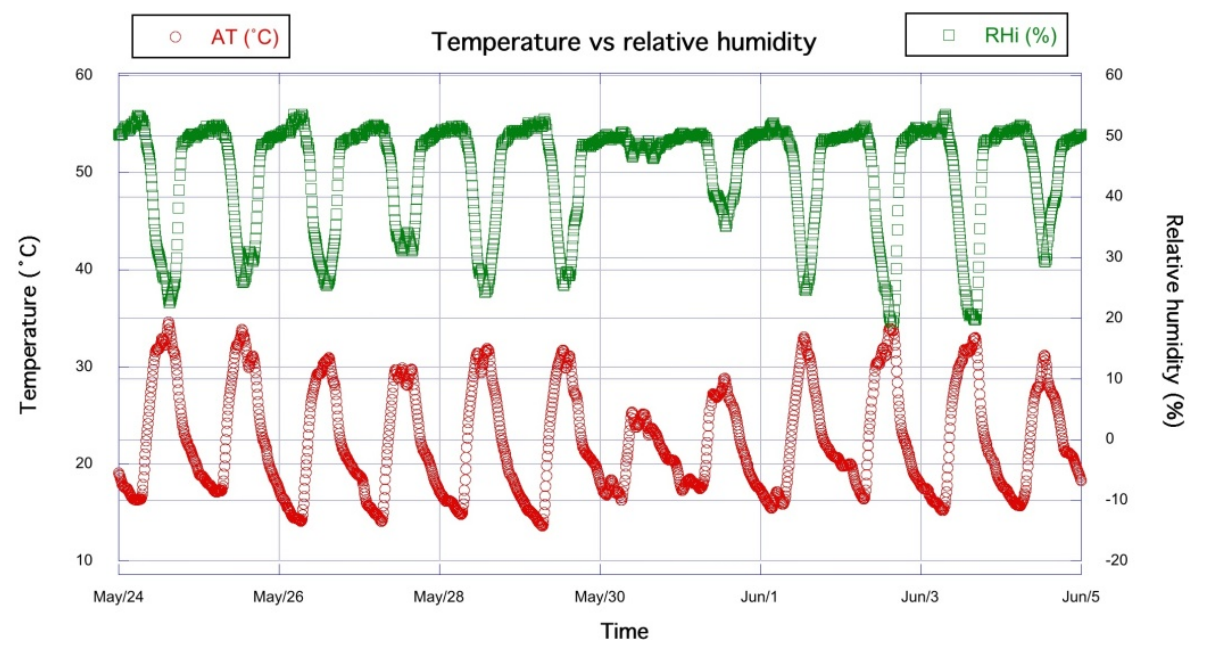

Fig. 15 Ambient temperature versus relative humidity.

well below condensation at all time, but there may be transient condensation on small dust particles nevertheless.

We would expect high dust concentration in the air when it is most windy but in fact the opposite is true. The winds speed increases as temperature decreases, in the late afternoon as shown in Figs. 16 and 17. The highest dust composition occurs as the temperature is rising and the air is quite still. Contrary to expectation, the dust concentration is quite low when the wind speed picks up in the late afternoon.

Returning the observation noted earlier that, the high dust events are infrequent. On most days, the dust concentration in the air does not exceed more that $50 \mathrm{mg} / \mathrm{m}^{3}$ but on rare occasions (approximately twice a month), the dust concentration suddenly shoots up to $1,000-2,000 \mathrm{mg} / \mathrm{m}^{3}$, over a $2-3$ hour time interval. We have not yet identified the source of the increase in dust level but it is likely to be related to an activity in the adjacent coal-mine. 


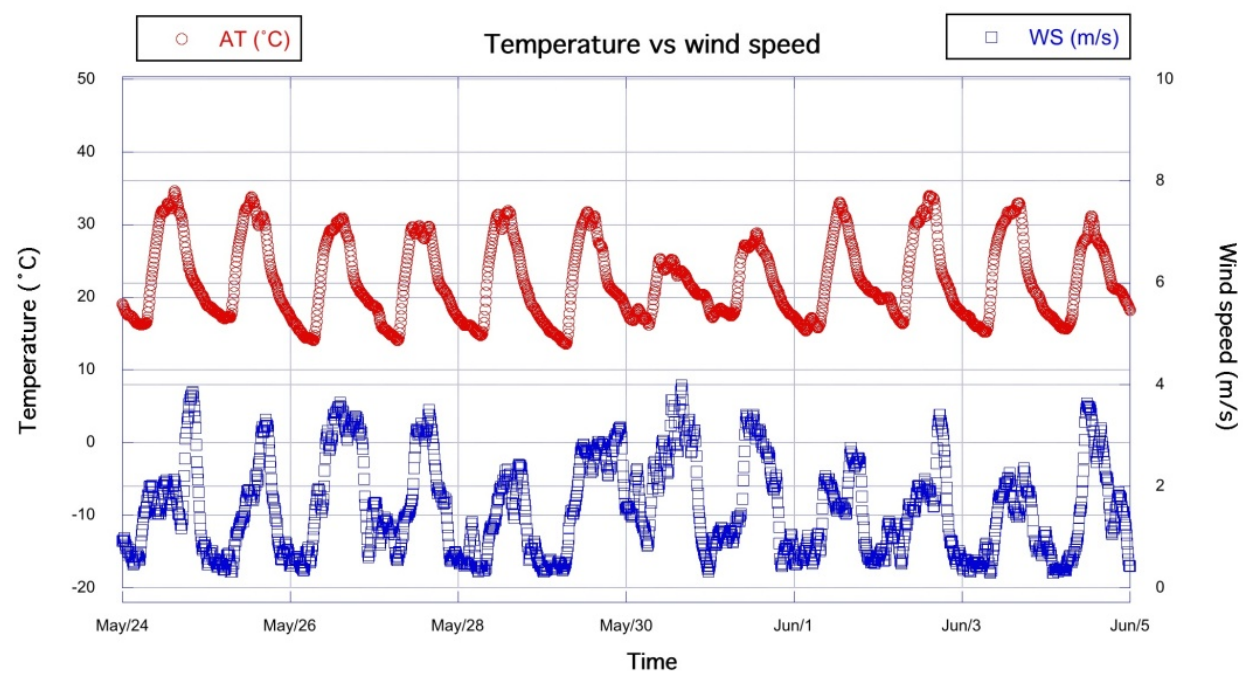

Fig. 16 Ambient temperature versus WS (wind speed).

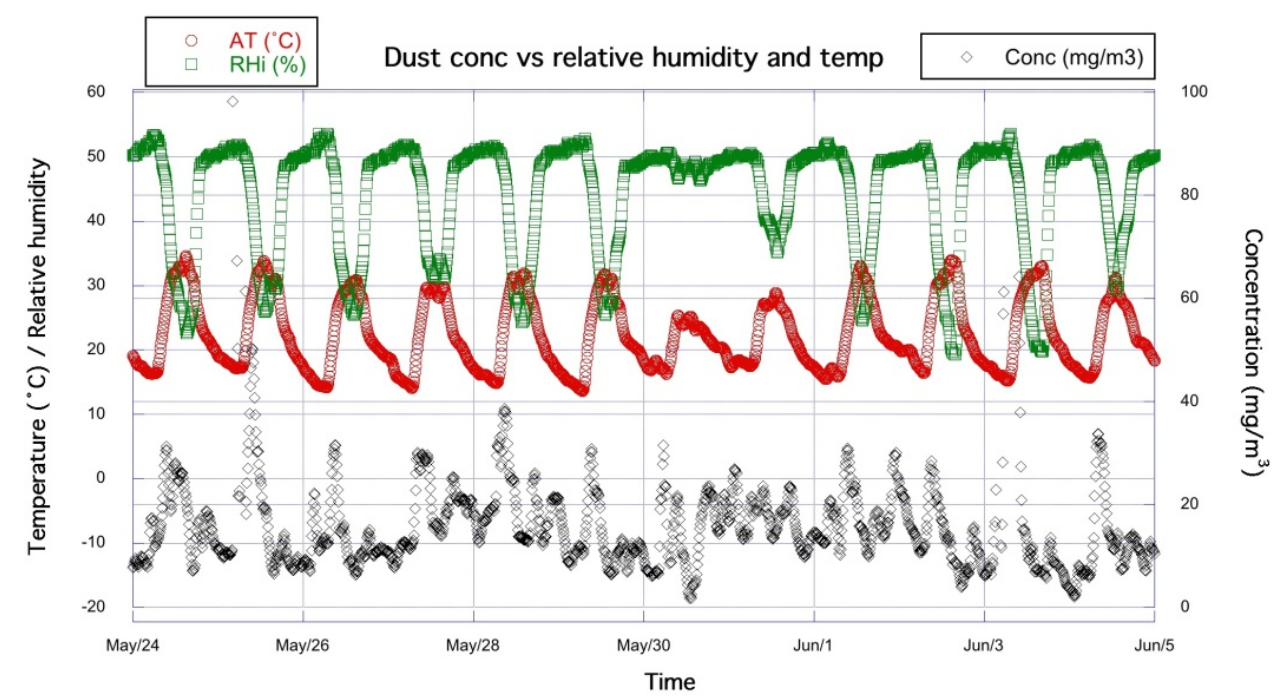

Fig. 17 Dust concentration versus ambient temperature and relative humidity.

\section{Conclusions}

In this paper, an analysis on climatic parameters affecting dust accumulation on CSP reflectors has been conducted. This study is equipped with a chemical analysis of dust accumulated on the north part of the Queensland state in Australia by a real-time monitor system based on the Ecotech E-sampler light scattering monitor.

This system is characterized by a dual technology, the light scattering technology and the gravimetric method. The first one provided real time measurements of airborne particulate by light scatter, while the second provides the calibration factor for the measurement of the light scattering and particulate characterization for size and properties analysis by the $47 \mathrm{~mm}$ filter. To provide the best accuracy of the dust concentration, a monitor calibration has been carried out in order to determine the " $K$-factor" as the ratio between the dust accumulated on the $47 \mathrm{~mm}$ filter, and the total concentration measured by the light scattering method at the same time interval. The average value of the $K$-factor for the system is 4.5 .

SEM analysis has provided an average particle size of $15 \mu \mathrm{m}$. The majority of the dust particles are clay-like (common dirt) while, in addition, there is a significant level of sea-salt in the air. 
In classify dust, there are two coarse categories, silicacious and abrasive or clay-like and sticky. The dust at Collinsville falls into the category of clay-like and sticky.

The highest level of dust in the air occurs in the early morning while the temperature is rising. We can speculate that, the rising temperature and warming of the ground surface creates an updraft of air which brings the dust up with it. In the late afternoon with decreasing temperature, there may be a downdraft of air that traps the dust closer to the ground despite the fact that, the horizontal wind speed is much higher at that time

The data analysis did not provide any seasonal trends or strong correlations with time-of year.

These results suggest that, cleaning activities have to be carried out during first hours of the morning to be effective. The right scheduling of cleaning activities is of great importance in the $\mathrm{O} \& \mathrm{M}$ (operation and maintenance) plan, since they have a significant impact on the energy produced or loss because of higher plant reflectivity restoration or a higher downtime for cleaning purpose.

\section{Acknowledgments}

This research was performed as part of the ASTRI (Australian Solar Thermal Research Initiative), a project supported by the Australian government, through the ARENA (Australian Renewable Energy Agency). We also acknowledge the support of the CSIRO (Commonwealth Scientific and Industrial Research Organisation), QUT and the UQ (University of Queensland).

\section{References}

[1] Fernández-García, A., Álvarez-Rodrigo, L., Martínez-Arcos, L., Aguiar, R., and Márquez-Payés, J. 2014. "Study of Different Cleaning Methods for Solar Reflectors Used in CSP Plants." Energy Procedia 49 (June): 80-9.

[2] Fernández-García, A., Cantos-Soto, M. E., León, J., and
López-Martín, R. 2010. “Optimization of Some Key Aspects of CSP Plants Maintenance, Fuels and Clean Water Power by the Sun." Presented at the Solar Power and Chemical Energy Systems 2010, Perpignan, France.

[3] Fernandez-Garcia, A., Zarza, E., Valenzuela, L., and Pérez, M. 2010. "Parabolic-Trough Solar Collectors and Their Applications." Renewable and Sustainable Energy Reviews 14 (7): 1695-721.

[4] El-Nashar, A. M. 2009. "Seasonal Effect of Dust Deposition on a Field of Evacuated Tube Collectors on the Performance of a Solar Desalination Plant." Desalination 239 (4): 66-81.

[5] Kaldellis, J. K., Fragos, P., and Kapsali, M. 2011. "Systematic Experimental Study of the Pollution Deposition Impact on the Energy Yield of Photovoltaic Installations." Renewable Energy 36 (10): 2717-24.

[6] Lovegrove, K., and Stein, W. 2012. Concentrating Solar Power Technology: Principles, Developments and Applications. USA: Woodhead Publishing Series in Energy.

[7] Mani, M., and Pillai, R. 2010. "Impact of Dust on Solar Photovoltaic (PV) Performance: Research Status, Challenges and Recommendations." Renewable and Sustainable Energy Reviews 14 (9): 3124-31.

[8] Cuddihy, E. F. 1983. Surface Soiling: Theoretical Mechanisms and Evaluation of Low-Soiling Coatings. Williamsburg, VA: JPPUD4, 379-96.

[9] Anglani, F., Barry, J., Dekkers, W., and Khare, S. 2015. "CFD Modelling of a Water-Jet Cleaning Process for Concentrated Solar Thermal (CST) Systems." Presented at the 3rd Southern African Solar Energy Conference, Kruger National Park, South Africa.

[10] Goossens, D., and Van Kerschaever, E. 1999. "Aeolian Dust Deposition on Photovoltaic Solar Cells: The Effects of Wind Velocity and Airborne Dust Concentration on Cell Performance." Solar Energy 66 (7): 277-89.

[11] Cohen, G. E., Kearney, D. W., and Kolb, G. J. 1999. "Final Report on the Operation and Maintenance Improvement Program for Concentrating Solar Power Plants." Usage listed is raw water usage and assumed to be withdrawal rate.

[12] Roth, E. P., and Anaya, A. J. 1980. "The Effect of Natural Soiling and Cleaning on the Size Distribution of Particles Deposited on Glass Mirrors." Journal of Solar Energy Engineering 102 (4): 248-56.

[13] Musselman, R. P., and Yarbrough, T. W. 1987. "Shear Stress Cleaning for Surface Departiculation." Journal of Environmental Sciences 30 (1): 51-6. 